\title{
An Assessment of the Association Between Smoking Status, Pain Intensity, and Functional Interference in Patients with Chronic Pain
}

Toby N. Weingarten, MD, Susan M. Moeschler, MD, Anne E. Ptaszynski, MD,

W. Michael Hooten, MD, Timothy J. Beebe, PhD, and David O. Warner, MD

From: Department of Anesthesiology, Department of Psychiatry and Psychology, and the Section of Biostatistics, Mayo Clinic and

Mayo Foundation, Rochester, MN.

Dr. Weingarten is an Assistant Professor of Anesthesiology, Mayo Clinic, Rochester, MN. Dr. Moeschler is a Resident in Anesthesiology, Mayo Clinic, Rochester, MN. Dr. Ptaszynski is a Fellow in Pain Medicine, Mayo Clinic, Rochester,

MN. Dr. Hooten is an Assistant Professor of Anesthesiology, and Psychiatry and Psychology

Mayo Clinic, Rochester, MN. Dr. Beebe is an

Associate Professor of Biostatistics, Mayo Clinic, Rochester, MN. Dr. Warner is a Professor of Anesthesiology, Mayo Clinic, Rochester, MN.

Address correspondence:

Toby N. Weingarten, MD

Department of Anesthesiology, Mayo Clinic 200 First Street SW

Rochester, MN 55905

E-mail: weingarten.toby@mayo.edu

Disclaimer: A portion of the data from this study has been presented in abstract form at: Moeschler SM, Ptaszynski AE, Hooten WM, Warner DO, Weingarten TN. Smoking behavior in patients presenting to a pain clinic with chronic back pain. Midwest Anesthesia Residents Conference - St Louis, MO 2007 April. Moeschler SM, Weingarten TN, Hooten WM, Warner DO. Smoking related gender differences among patients evaluated in a tertiary pain clinic. American Academy of Pain Medicine 24st Annual Meeting - Orlando, FL 2008 February. A portion has been submitted in abstract form to the 2008 annual American Society of Anesthesiologists in Orlando, FL.

Support: Supported by the Department of Anesthesiology, Mayo Clinic and Mayo Foundation, Rochester, MN. Conflict of interest: None.

Manuscript received: 06/04/2008 Revised manuscript received: 07/23/2008 Accepted for publication: $07 / 29 / 2008$

Free full manuscript: www.painphysicianjournal.com
Background: This article examines the association between smoking and pain intensity and functional interference in a heterogeneous group of patients evaluated at a tertiary outpatient pain clinic. Current smoking is associated with less favorable clinical presentations.

Objective: This study was conducted to determine if the smoking status of patients seen in an outpatient pain clinic is associated with differences in pain intensity and interference.

Methods: Surveys were mailed to 500 consecutive new patients evaluated at an outpatient pain clinic. Measures included the Brief Pain Inventory (BPI) and the Fagerström Test for Nicotine Dependence (FTND). Univariate analyses compared BPI scores between smokers and non-smokers. Mean BPI scores were compared between smoking status via analysis of covariance (adjusted for demographic variables which differed significantly by smoking status). A $p$ value $\leq 0.05$ was accepted as significant.

Results: Survey completion rate was $46 \%$, and $14.7 \%$ were current smokers. Smokers were younger, and more likely to be male and unemployed. Smokers had higher scores on all the pain intensity BPI scales $(p<0.01)$, and higher scores (indicating greater functional impairment) on the general activity $(p=0.007)$, mood $(p=0.003)$, normal work $(p=0.02)$, relationships $(p=0.04)$, sleep $(p<0.001)$, and life enjoyment $(p=0.03)$ BPI functional impairment scales. Severe nicotine dependence was associated with greater pain now, $(p=0.05)$, and greater functional interference on mood ( $p=$ $0.005)$, normal work $(p=0.02)$ and life enjoyment $(p=0.04)$ BPI scales.

Conclusion: In patients who completed evaluation in an outpatient pain clinic, current cigarette smokers reported significantly greater pain intensity and pain interference with functioning. Symptoms were more pronounced in smokers with more severe nicotine dependence.

Key words: smoking status; outpatient pain management; brief pain inventory; Fagerström test for nicotine dependence

Pain Physician 2008; 11:5:643-653 
n 2006, 20.1\% of adults in the United States were smoking cigarettes (1). Epidemiologic studies have suggested that cigarette smoking may be associated with painful musculoskeletal disorders (2-5). Smokers are also more likely to use analgesic medications than people who have never smoked (6). Among patients with chronic pain, current cigarette smokers may experience worse pain symptoms than non-smokers (2). For example, cigarette smokers enrolled in a national spine network database have more severe back pain and lower scores on all the subscales of the SF-36, a measure of functional status, than non-smokers (7). Patients with fibromyalgia who smoke cigarettes have greater pain intensity and functional impairment than non-smokers with fibromyalgia $(8,9)$.

Outpatient pain clinics evaluate and treat a heterogenous group of patients with a variety of chronic pain disorders. There is no published data regarding any possible associations between current tobacco use and pain intensity and functional interference in this patient population. The aim of this study is to characterize the rate of smoking among patients seen in a tertiary outpatient pain clinic and determine if smoking status is associated with differences in pain intensity function.

\section{Methods}

This study was approved by the Mayo Clinic Institutional Review Board. The Mayo Clinic outpatient pain clinic is a tertiary referral center for patients with chronic pain. The pain clinic is staffed by board-certified pain specialists. Patients treated at the pain clinic undergo a comprehensive evaluation and depending on their clinical presentation are offered interventional treatments, pharmacologic recommendations, physical therapy, and/or referral to pain rehabilitation with emphasis on cognitive behavior therapy. Patients are referred to the pain clinic from within the Mayo Clinic system. Ninety-five percent of patients evaluated are Caucasian and from the upper Midwest. During the clinical assessment at the initial visit to the pain clinic, subjects undergo a standardized preliminary evaluation with a registered nurse where demographic variables and current smoking status are ascertained and entered into the electronic medical record. Previous smoking history (former smoker or never a smoker) is abstracted from a general past medical history intake questionnaire that all patients at the Mayo Clinic complete and is included in their electronic medical records. This questionnaire asks subjects if they are previous smokers and how long they had stopped smoking; and, if they currently smoked or use tobacco products, how motivated they are to quit (not motivated, somewhat motivated, very motivated).

A written survey was mailed in September of 2007 to a consecutive series of 500 adult patients that underwent an initial assessment at the Mayo Clinic outpatient pain clinic for pain not related to cancer from September 2006 to February 2007. Non-responders received a follow up letter and a telephone call reminding them to complete the survey. All subjects had provided prior written consent to participate in research protocols. After receiving the mailed survey, 3 subjects requested to be withdrawn from the study and were excluded from further analysis.

The mailed survey contained the Brief Pain Inventory (BPI) and the Fagerström Test for Nicotine Dependence (FTND) (10-13). The BPI is a tool to assess pain intensity and the degree to which pain interferes with function, and has been validated in patients with noncancer pain (Fig. 1) $(14,15)$. Patients rate their pain severity on an 11-point scale over several time periods. A similar 11-point scale is used to rate the degree to which the pain interferes with 7 areas of the patient's life: general activity, mood, walking ability, normal work, relationships, sleep, and enjoyment of life. The 6 -item FTND is a revised and abbreviated version of the Fagerström Tolerance Questionnaire (Fig. 2) (10-12). The questionnaire assesses for clinical indicators of dependence, including the number of cigarettes smoked per day and difficulty refraining from smoking when it is not allowed. Scores from the FTND range from 0 to 10 , with scores greater than or equal to 6 indicating severe nicotine dependence.

The initial pain consult note, the nursing preliminary interview, and responses to the general past medical history intake questionnaire stored in the electronic medical record of subjects that responded to the written survey were abstracted for data regarding demographic variables, primary site of body pain, treatment received during the initial pain clinic visit, current and past tobacco use, and readiness to quit tobacco.

\section{Statistical Analysis}

Univariate analyses were performed to detect differences between demographic variables and BPI scores between smokers and non-smokers, and smokers, people who have never smoked, and former smokers. Repeat measures analysis of covariance (ANCOVA) 


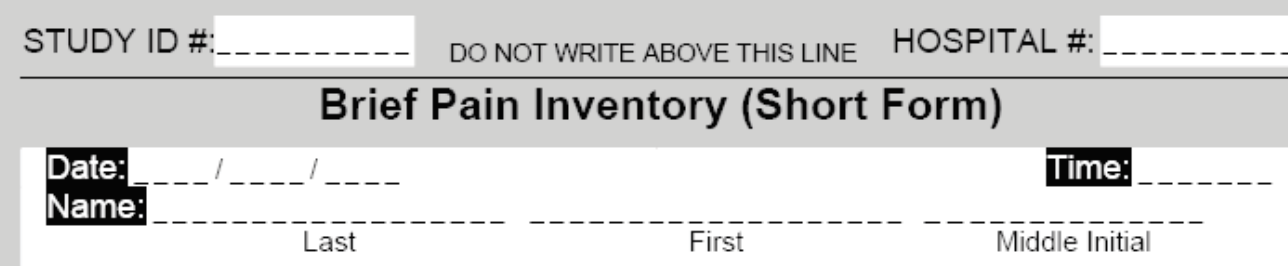

1. Throughout our lives, most of us have had pain from time to time (such as minor headaches, sprains, and toothaches). Have you had pain other than these everyday kinds of pain today?
1. Yes
2. No

2. On the diagram, shade in the areas where you feel pain. Put an $\mathrm{X}$ on the area that hurts the most.

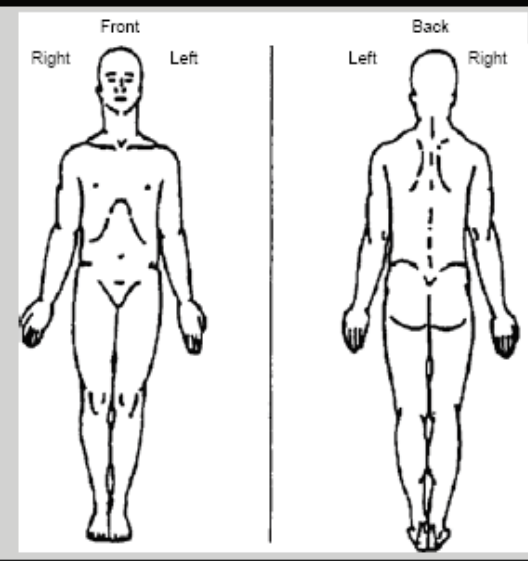

3. Please rate your pain by circling the one number that best describes your pain at its worst in the last 24 hours.

$\begin{array}{lllllllllll}0 & 1 & 2 & 3 & 4 & 5 & 6 & 7 & 8 & 9 & \begin{array}{l}10 \\ \text { Pain as bad as } \\ \text { you can imagine }\end{array} \\ \text { Pain } & & & & & & & & & & \end{array}$

4. Please rate your pain by circling the one number that best describes your pain at its least in the last 24 hours.

\begin{tabular}{lllllllllll}
0 & 1 & 2 & 3 & 4 & 5 & 6 & 7 & 8 & 9 & $\begin{array}{l}10 \\
\text { Pain as bad as } \\
\text { No } \\
\text { Pain }\end{array}$ \\
\hline
\end{tabular}

5. Please rate your pain by circling the one number that best describes your pain on the average.

\begin{tabular}{lllllllllll}
0 & 1 & 2 & 3 & 4 & 5 & 6 & 7 & 8 & 9 & $\begin{array}{l}10 \\
\text { Pain as bad as } \\
\text { you can imagine }\end{array}$ \\
Pain & & & & & & & & & & \\
\hline
\end{tabular}

6. Please rate your pain by circling the one number that tells how much pain you have right now.

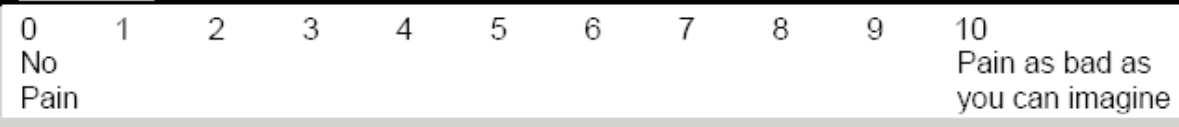

Page 1 of 2

Fig. 1. Brief Pain Inventory (BPI) Page 1.

Copyright 1991 Charles S. Cleeland PhD, Pain Research Group. Used by permission. 
Pain Physician: September/October 2008:11:643-653

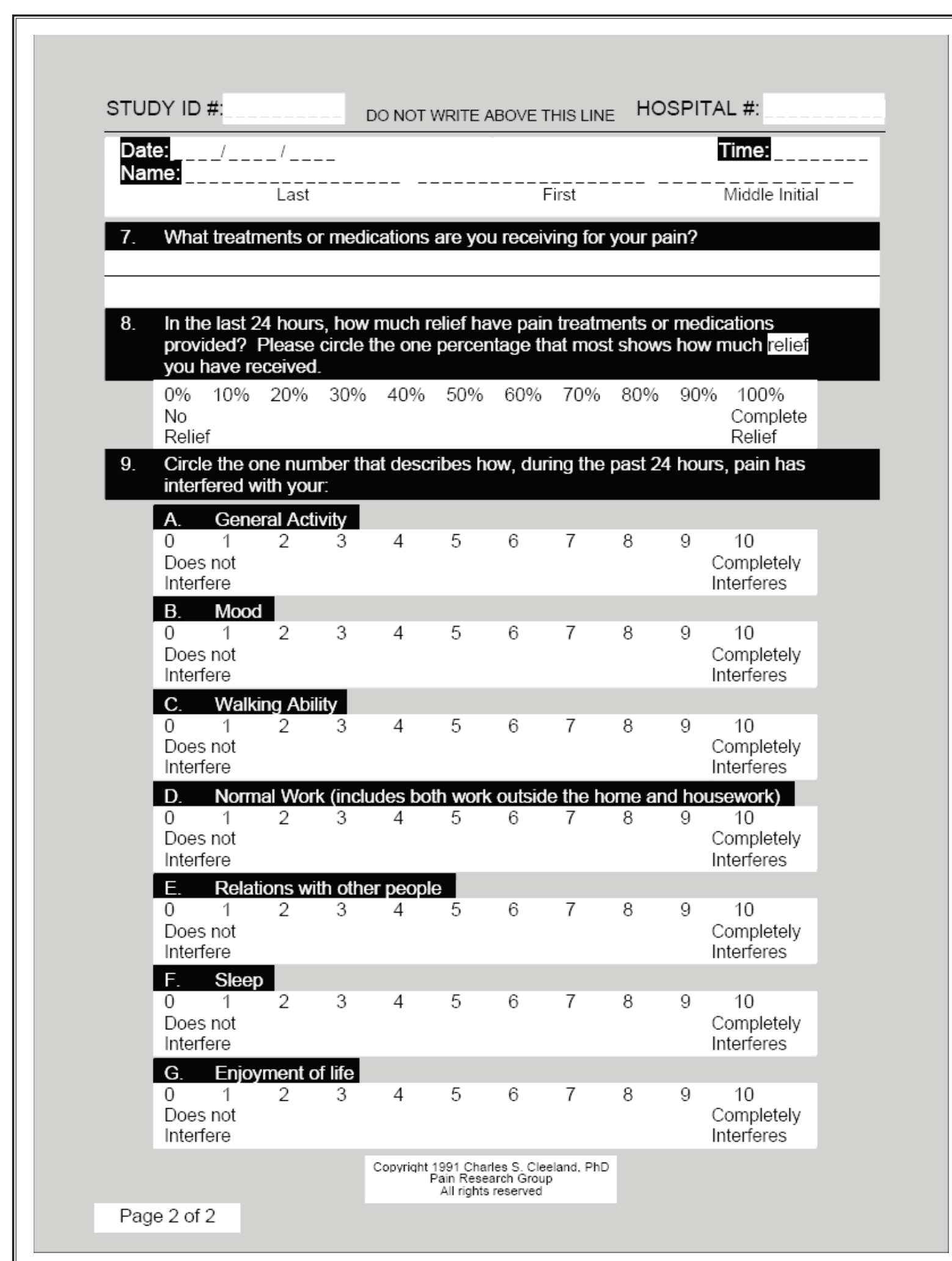

Fig. 1 (cont.) Brief Pain Inventory (BPI) Page 2.

Copyright 1991 Charles S. Cleeland PhD, Pain Research Group. Used by permission. 
was also conducted to compare mean BPI scores by smoking status, adjusting for covariates which were found to be significantly different between smokers and non-smokers (age, gender, employment status). To determine whether the degree of nicotine dependence was associated with the severity of pain symptoms, univariate analyses were performed to determine if differences existed in BPI pain intensity and functional interference sub-scales between smokers with severe nicotine addiction (FTND $\geq 6$ ) versus moderate to mild addiction (FTND < 6). In all cases, a 2tailed $p$ value of $\leq 0.05$ was considered significant. All analyses were completed using SPSS (Version 16.0).

\section{Results}

Surveys were mailed to 500 patients; 230 (46\%) completed and returned the survey. Thirty-three $(14.7 \%)$ respondents reported current use of tobacco, defined as current use of cigarettes, $112(51.1 \%)$ respondents had never used tobacco products, and 74 $(33.8 \%)$ respondents had previously used tobacco products. Sixty-seven $(90.5 \%)$ of the former smokers had abstained from cigarettes for greater than one year. Current smokers were significantly more likely to be male, younger, and unemployed than never and/or former smokers (Table 1). Never smokers were better educated than current and former smokers, and former smokers were older and more likely to be retired than current and never smokers (Table 1). Current smokers, never smokers, and former smokers did not significantly differ in terms of marital status and educational level. The anatomic site of the primary painful condition that prompted the visit to the pain clinic did not differ between smokers and non-smokers. During the subjects' initial evaluation at the pain clinic, smokers compared to current non-smokers were more likely to be referred to a pain rehabilitative program (27.3\% vs $12.0 \%, p=0.02$ ).

Preliminary analyses revealed that there were no significant differences between never smokers and former smokers in any BPI pain intensity and functional interference scales (data not shown). Therefore, never and former smokers were combined in subsequent analyses. Compared to non-smokers, smokers reported greater pain intensity on all the BPI intensity pain scales, and reported greater pain interference on the general activity, mood, normal work, relationships, sleep, and life enjoyment BPI pain interference subscales (Table 2). These findings remained significant, except for the normal work and relationships sub-
1. How soon after you wake up do you smoke your first cigarette?

$\square$ Within 5 minutes
$\square 6-30$ minutes
$\square 31-60$ minutes
$\square$ After 60 minutes

2. Do you find it difficult to refrain from smoking in places where it is forbidden, e.g. in church, at the library, in the cinema, etc.?
$\square$ No
$\square$ Yes

3. Which cigarette would you hate most to give up? $\square$ The first one in the morning $\square$ Any other

4. How many cigarettes do you smoke a day? (For the 30 days prior to coming to this visit.)

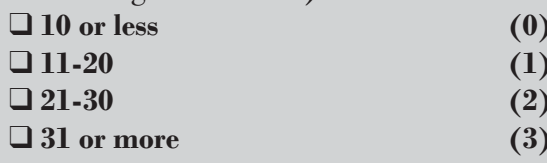

5. Do you smoke more frequently in the first hours after waking than during the rest of the day?
$\square$ No
$\square$ Yes

6. Do you smoke even if you are so ill that you are in bed most of the day?

$\square$ No
$\square$ Yes

$\begin{array}{ll}\text { Score: } & \\ 0-2 & \text { Very low dependence } \\ 3-4 & \text { Low dependence } \\ 5 & \text { Medium dependence } \\ \text { 6-7 } & \text { High dependence } \\ \text { 8-10 } & \text { Very high dependence }\end{array}$

Fig. 2. Fagerström Test for Nicotine Dependence (11).

scales, even after analysis of covariance (ANCOVA) adjusted for significant differences in demographic variables including gender, age and employment status.

For current smokers who responded to the survey, $29 / 33(88 \%)$ completed the FTND, with a mean score of $4.7 \pm 2.0$ [M $\pm S \mathrm{D}]$. Eleven respondents $(37.9 \%)$ reported a FTND $\geq 6$, indicating severe nicotine dependence. Smokers with severe nicotine dependence had higher BPI pain now scores (7.36 \pm 2.06 vs. $5.39 \pm 2.81$, $p=0.05)$, BPI mood sub-scale $(8.00 \pm 2.24$ vs. $5.06 \pm$ 
Table 1. Demographic and clinical characteristics of subjects presenting to an outpatient pain clinic by smoking status.

\begin{tabular}{|c|c|c|c|c||}
\hline \hline & $\begin{array}{c}\text { Current Smokers } \\
(\mathbf{N = 3 3})\end{array}$ & $\begin{array}{c}\text { Never Smokers } \\
(\mathbf{N = 1 1 2})\end{array}$ & $\begin{array}{c}\text { Former Smokers } \\
(\mathbf{N}=\mathbf{7 4})\end{array}$ & $\boldsymbol{p}$-value \\
\hline \multicolumn{3}{|c|}{$\mathrm{N}(\%)$ Mean $(\mathrm{SD})$} \\
\hline
\end{tabular}

Gender*

0.001

\begin{tabular}{|l|c|c|c|c|c|}
\hline Male & $21(63.6)$ & $32(28.6)$ & $29(39.2)$ \\
\hline Female & $12(36.4)$ & $80(71.4)$ & $45(60.8)$ \\
\hline Age & $51(11)$ & $57(15)$ & $63(12)$ \\
\hline
\end{tabular}

Education $^{*}$

0.004

\begin{tabular}{|c|c|c|c|c|}
\hline Did not complete high school & $3(10.0)$ & $3(2.9)$ & $4(5.7)$ & \\
\hline High school/GED & $9(30.0)$ & $26(25.2)$ & $25(35.7)$ & \\
\hline Some college & $13(43.3)$ & $24(23.3)$ & $25(35.7)$ & \\
\hline College degree & $5(16.7)$ & $50(48.5)$ & $16(22.9)$ & \\
\hline \multicolumn{4}{|l|}{ Employment* } & $<0.001$ \\
\hline Employed & $9(28.1)$ & $54(49.1)$ & $17(23.3)$ & \\
\hline Unemployed & $16(50.0)$ & $18(16.4)$ & $16(21.9)$ & \\
\hline Retired & $5(15.6)$ & $32(29.1)$ & $38(52.1)$ & \\
\hline Homemaker & $2(6.2)$ & $6(5.5)$ & $2(2.7)$ & \\
\hline \multicolumn{4}{|l|}{ Marital Status } & 0.12 \\
\hline Married & $21(63.6)$ & $85(75.9)$ & $51(69.9)$ & \\
\hline Not currently married & $12(36.4)$ & $19(17.0)$ & $17(23.3)$ & \\
\hline Widowed & $0(0)$ & $8(7.1)$ & $5(6.8)$ & \\
\hline \multicolumn{4}{|l|}{ Site of Pain } & 0.56 \\
\hline Back/Leg & 13(39.4) & $59(52.7)$ & $37(50.0)$ & \\
\hline Neck/Arm & $5(14.7)$ & $18(16.1)$ & $9(12.2)$ & \\
\hline Chest/Abdomen & $7(15.2)$ & $21(18.8)$ & $18(24.3)$ & \\
\hline Multisite pain & $4(12.1)$ & $9(8.0)$ & $8(10.8)$ & \\
\hline Headache & $4(12.1)$ & $5(4.5)$ & $2(2.7)$ & \\
\hline \multicolumn{5}{|c|}{ Treatment received during initial pain clinic visit } \\
\hline Procedural therapy ${ }^{\star}$ & $10(30.3)$ & $62(55.7)$ & $33(45.2)$ & 0.03 \\
\hline Pharmacologic recommendations & $23(69.7)$ & $69(61.6)$ & $48(65.8)$ & 0.66 \\
\hline Physical therapy & $8(24.2)$ & $40(35.7)$ & $23(31.5)$ & 0.45 \\
\hline $\begin{array}{l}\text { Referral to pain rehabilitative } \\
\text { program }\end{array}$ & $9(27.3)$ & 13(11.6) & $10(13.7)$ & 0.08 \\
\hline
\end{tabular}

*Mean differences between smokers, life-long non-smokers, and former smokers are significant at the 0.05 level $\mathrm{GED}=$ general equivalency diploma. 
The Association Between Smoking and Pain Symptoms

Table 2. Impact of smoking status on pain intensity and interference on patients treated at an outpatient pain clinic.

\begin{tabular}{|c|c|c|c|c|}
\hline & Smokers & Non-Smokers & $p$ value & Adjusted Analysis* \\
\hline & Mean(SD) & Mean(SD) & & \\
\hline \multicolumn{5}{|l|}{ BPI Pain Intensity } \\
\hline Worst $† \$$ & $7.55(2.33)$ & $6.09(2.49)$ & 0.002 & {$[\mathrm{~F}(1,207)=10.16, P=0.002]$} \\
\hline Least $† S$ & $4.06(2.33)$ & $2.98(2.04)$ & 0.007 & {$[\mathrm{~F}(1,210)=8.50, P=0.004]$} \\
\hline Average $† s$ & $5.87(2.03)$ & $4.78(2.14)$ & 0.01 & {$[\mathrm{~F}(1,200)=9.44, P=0.002]$} \\
\hline Nowts & $6.09(2.79)$ & $4.52(2.41)$ & 0.001 & {$[\mathrm{~F}(1,210)=13.61, P<0.001]$} \\
\hline \multicolumn{5}{|l|}{ BPI Pain Interference } \\
\hline General Activity $\dagger \S$ & $6.44(3.05)$ & $5.00(2.78)$ & 0.007 & {$[\mathrm{~F}(1,215)=7.98, P=0.005]$} \\
\hline Mood $† \S$ & $6.44(2.84)$ & $4.56(2.79)$ & 0.003 & {$[\mathrm{~F}(1,214)=6.48, P=0.01]$} \\
\hline Walking§ & $5.47(3.44)$ & $4.59(3.36)$ & 0.16 & {$[\mathrm{~F}(1,214)=4.26, P=0.04]$} \\
\hline Normal Work $\dagger$ & $6.55(3.30)$ & $5.21(3.08)$ & 0.02 & {$[\mathrm{~F}(1,212)=3.49, P=0.06]$} \\
\hline Relationships $\dagger$ & $4.74(3.19)$ & $3.59(2.89)$ & 0.04 & {$[\mathrm{~F}(1,212)=2.86, P=0.09]$} \\
\hline Sleept\$ & $7.19(2.75)$ & $4.97(3.12)$ & $<0.001$ & {$[\mathrm{~F}(1,215)=10.51, P=0.001]$} \\
\hline Life Enjoyment $\dagger \$$ & $6.66(3.14)$ & $5.27(3.16)$ & 0.03 & {$[\mathrm{~F}(1,213)=5.60, P=0.02]$} \\
\hline
\end{tabular}

*Adjusted for statistically significant differences between groups on age, gender, employment status.

† Significant difference with univariate analysis

$\S$ Significant difference with adjusted analysis

$\mathrm{SD}=$ Standard Deviation. BPI = Brief Pain Inventory

$2.67, p=0.005)$, BPI normal work sub-scale $(8.73 \pm 1.62$ vs $5.94 \pm 3.34, p=0.02$ ), and BPI enjoyment of life subscale $(8.27 \pm 1.62$ vs. $6.00 \pm 3.31, p=0.04)$. For current smokers, $11(44.0 \%)$ reported that they were somewhat interested and $3(12.0 \%)$ reported that they were very interested in quitting smoking.

\section{Discussion}

Little is known about the smoking status of patients seen in pain clinics, despite epidemiologic and clinical evidence suggesting a link between tobacco use and pain of various forms. In our study, current tobacco use among survey respondents was associated with greater pain intensity as measured by all BPI pain intensity scales. Studies of different patient populations have also demonstrated that smoking is associated with greater pain intensity. For example, among patients with fibromyalgia, smokers report greater pain intensity than non-smokers $(8,9)$. Smokers enrolled in the national spine network database have more severe back pain and lower, indicating worse, SF-36 body pain scores (7). Population-based studies in Great Britain, Norway, and Germany also found that tobacco use was associated with more severe symptoms from musculoskeletal disorders (2-4). The redun- dancy of findings among different studies suggests that our observation that smoking is associated with greater pain intensity may generalize to other chronic pain conditions.

The higher levels of pain reported by smokers in this survey was also associated with greater pain functional interference on general activity, mood, sleep, and life enjoyment BPI sub-scales with the greatest differences present on the mood and sleep sub-scales. The association between smoking and mood disorders is well known and our results may represent a higher rate of mood disorders among the subjects that smoke (16-18). The interactions between depression and pain have also been well recognized (19). The interaction between these 3 variables in patients with chronic pain, if any, is currently unknown. Smokers enrolled in the national spine network database were found to have more depressive symptoms than non-smokers (7). However, smoking status did not affect measurements of depression in patients enrolled at both a chronic pain management center and patients with fibromyalgia treated at a fibromyalgia clinic $(8,20)$. A limitation of this study is that subjects were not formally assessed for mood disorders such as depression or anxiety. The presence of such disorders could represent 
a confounding factor in our results and is a potential area for further study. Smoking has been associated with a higher prevalence of sleeping disorders in epidemiologic studies (21-23). Smoking related differences in sleep architecture as measured by polysomnography have been observed, smokers have a longer latency to sleep onset and spend a greater percentage in lighter stages of sleep (23). Impaired sleep is well known among patients with pain and has been associated with greater pain intensity as well as increased depressive symptoms and anxiety $(24,25)$. It is unknown if smoking exacerbates sleep disorders among patients with chronic pain. Our findings suggest that a relationship between current smoking, poor sleep, and pain does exist in patients evaluated in a pain clinic. The observation that smokers were more likely to be referred to cognitive behavioral therapy pain rehabilitation programs and less likely to be offered a procedure during their initial assessment at the pain clinic probably reflects greater functional impairment in these subjects. Subjects referred to these programs had greater pain intensity and functional interference than other subjects regardless of their smoking status. Also in our practice, subjects with obvious and overbearing behavior dysfunction arising from a painful condition are less likely to be offered a procedure.

We found no differences between never and former smokers in any variable studied. Several epidemiologic studies suggest that there is a higher prevalence of chronic pain in former smokers, who were more likely to use analgesic medications than never smokers (3-6). In our study, former smokers were older and more often retired, and these differences may have minimized the clinical presentation of their painful condition because physical demands placed on these subjects were less. Another explanation is that former smokers developed their painful disorder long after they quit smoking and any deleterious effects of cigarettes had previously resolved. Alternatively, perhaps smoking cessation is therapeutic and former smokers improved to resemble never smokers. However, in this study we did not attempt to determine the existence of a temporal relationship between the timing of smoking cessation and the evolution of the subjects' pain disorders.

We found that $14.7 \%$ of the survey responders were current smokers, $51.1 \%$ had never used tobacco products, and $33.8 \%$ were former tobacco users. This is the same rate of smoking we found among patients with fibromyalgia that were treated in a spe- cialized fibromyalgia treatment center (9). The rate of cigarette use in the respondents was lower than the overall national prevalence of cigarette use of $20.6 \%$ (1), but comparable to the rates observed in large series of patients with chronic pain, including a $15.3 \%$ smoking rate among 25,417 patients with rheumatic diseases that are enrolled in the National Data Bank for Rheumatic Disease and a $16.7 \%$ rate of smoking among 25,455 patients enrolled in the National Spine Network Database $(7,26)$. Population-based studies of non-specific musculoskeletal disorders found that smoking was associated with greater risk of having a painful disorder (2-4). However, the relationship between smoking and the development of low back pain is less clear. Two large systematic reviews of the literature regarding the association of low back pain and smoking status had somewhat conflicting results $(27,28)$. The Goldberg et al $(27)$ review of 38 studies concluded that smoking was associated with an increased incidence of nonspecific low back pain, but the Leboeuf-Yde (28) review of 41 studies concluded that smoking was a weak risk indicator but not a cause for low back pain.

We also found that smoking status was related to various sociodemographic characteristics of our patient sample, such as age, gender, and employment status. These findings are consistent with prior studies of the general population of smokers (1). Smoking is associated with economic variables such as lower education level, higher rates of divorce, and unemployment that can also have an impact on pain syndromes (29-32). For example, patients enrolled in a chronic pain rehabilitation center are more likely to be involved in a workman's compensation claim (20). However, despite an observed association between current smoking status in our study subjects and these confounding variables, smoking was still associated with greater pain intensity and greater pain interference on several of the BPI pain interference sub-scales.

Subjects with severe nicotine dependence, as determined by the FTND score, reported greater pain intensity and greater pain interference on the BPI mood, normal work, and enjoyment of life sub-scales. We are not aware of other efforts to correlate pain intensity and the degree of nicotine dependence. The worse $\mathrm{BPI}$ mood score is consistent with the finding of a prior study that depression is more prevalent in subjects that are dependent upon nicotine than subjects that use tobacco but are not dependent upon nicotine (18). 
Several mechanisms have been suggested to explain this association between the intensity of pain in chronic pain states and smoking status. Smoking has been associated with alterations of the levels of neuropeptides that play a role in chronic pain states. Patients with fibromyalgia that smoke have higher levels of substance $P$ in the cerebral spinal fluid (33). Smokers also have lower plasma beta-endorphin levels than non-smokers $(34,35)$. In contrast, in subjects without chronic pain, in experimental settings nicotine has antinociceptive effects in response to electrical, cold pressor, thermal, and ischemic pain stimuli (35-42). Clearly, more research is needed on nicotine effects on nociception in patients with chronic pain.

Our study focuses on a unique population group among which the existence of any possible associations between smoking status and clinical presentation has never been previously characterized. The relatively low response rate introduces the possibility of response bias. This would affect our results to the degree that responders would be more or less likely to report pain than non-responders, and whether this would depend upon smoking status. However, there is strong evidence that it is becoming more difficult to obtain a response rate of a historically acceptable level of $60 \%-70 \%$ as participation to general population surveys has been decreasing for some time despite the deployment of heroic measures to ensure response (43-45). Alreck and Settle (46) have commented on the problem of low response rate to mail surveys with most response rates often falling below 30\%. Moreover, recent evidence suggests only a weak relationship between a survey's response rates and response bias $(47,48)$. The low rate did bring about a lower than expected number of completed cases, thus decreasing the statistical power of the analyses. Also, this survey was administered after patients were evaluated and treated in our pain clinic, and thus included effects of any therapy provided. We cannot comment upon the potential effect of smoking status on pain treatment effect. Also our study sample represents patients treated at an outpatient pain clinic and results cannot be generalized to other patient populations. Nonetheless, our results add to the growing body of literature that suggests current tobacco use is associated with a worse clinical presentation in patients with pain.

In conclusion, in patients who completed evaluation in an outpatient pain clinic, current cigarette smokers reported significantly greater pain and interference of pain with functioning. Symptoms were more pronounced in smokers with more severe nicotine dependence. The clinical implications of these findings suggest that patients that smoke will have greater pain intensity and functional interference and may present a greater clinical challenge to pain clinicians. However, the observations in this study do raise many questions and could direct future research endeavors. It is unclear if current smoking status directly influences pain symptoms or if it is a marker for a confounding covariate such as a formal mood disorder. Further research also needs to be directed towards potential interactions between smoking and response to therapies for pain management. It is also unknown if tobacco abstinence would have an ameliorating affect on pain symptoms, but the observation that former smokers were clinically more like never smokers than current smokers suggests that it is prudent to offer these patients tobacco cessation therapy for general health reasons and to eliminate any theoretical deleterious affects from tobacco.

\section{Conclusion}

In patients who completed evaluation in an outpatient pain clinic, current cigarette smokers reported significantly greater pain intensity and pain interference with functioning. Symptoms were more pronounced in smokers with more severe nicotine dependence.

\section{References}

1. CDC. State-Specific Prevalence of Current Cigarette Smoking Among Adults and Secondhand Smoke Rules and Policies in Homes and Workplaces - United States, 2005. MMWR 2006; 55:11481151.

2. Eriksen WB, Brage S, Bruusgaard D. Does smoking aggravate musculoskeletal pain? Scandinavian Journal of Rheumatology 1997; 26:49-54.
3. Palmer KT, Syddall H, Cooper CDC. 5. Smoking and musculoskeletal disorders: Findings from a British national survey. Ann Rheum Dis 2003; 62:3336.

4. John U, Hanke M, Meyer C, Volzke H, Baumeister SE, Alte D. Tobacco smoking in relation to pain in a national 6 . general population survey. Preventive Medicine 2006; 43:477-481.
Andersson H, Ejlertsson G,Leden I. Widespread musculoskeletal chronic pain associated with smoking. An epidemiological study in a general rural population. Scandinavian Journal of Rehabilitation Medicine 1998; 30:195191.

John U, Alte D, Hanke M, Meyer C, Völzke $\mathrm{H}$, Schumann A. Tobacco smoking in relation to analgesic drug use in a na- 
tional adult population sample. Drug Alcohol Depend 2006; 85:49-55.

7. Vogt MT, Hanscom B, Lauerman WC, Kang JD. Influence of smoking on the health status of spinal patients: The National Spine Network Database. Spine 2002; 27:313-319.

8. Yunus MB, Arslan S, Aldag JC. Relationship between fibromyalgia features and smoking. Scandinavian Journal of Rheumatology 2002; 31:301-305.

9. Weingarten TN, Podduturu VR, Hooten WM, Thompson JM, Luedtke CA, Oh $\mathrm{TH}$. Impact of tobacco use in patients presenting to a multidisciplinary outpatient treatment program for fibromyalgia. Clinical Journal of Pain 2008; In press.

10. Fagerström KO. Measuring degree of physical dependence to tobacco smoking with reference to individualization of treatment. Addict Behav 1978; 3:235-341.

11. Heatherton TF, Kozlowski LT, Frecker RC, Fagerström KO. The Fagerström Test for nicotine dependence: A revision of the Fagerström tolerance ques tionnaire. Br J Addict 1991; 86:11191127.

12. Payne TJ, Smith PO, McCracken LM, McSherry WC, Antony MM. Assessing nicotine dependence: A comparison of the Fagerström tolerance questionnaire (FTQ) with the Fagerström test for nicotine dependence (FTND) in a clinical sample. Addict Behav 1994; 19:307-317.

13. Cleeland CS, Ryan KM. Pain assessment: Global use of the brief pain inventory. Ann Acad Med Singapore 1994; 23:129-138.

14. Keller S, Bann CM, Dodd SL, Schein J, Mendoza TR, Cleeland CS. Validity of the brief pain inventory for use in documenting the outcomes of patients with noncancer pain. Clin J Pain 2004; 20:309-318.

15. Tan G, Jensen MP, Thornby JI,Shanti BF. Validation of the Brief Pain Inventory for chronic nonmalignant pain. J Pain 2004;5:133-137.

16. Breslau N, Kilbey MM, Andreski P. Nicotine dependence and major depression: New evidence from a prospective investigation. Arch Gen Psychiatry 1993; 50:31-35.

17. Breslau N, Peterson EL, Schultz LR, Chilcoat HD, Andreski P. Major depres- sion and stages of smoking: a longitudinal investigation. Arch Gen Psychiatry 1998; 55:161-166 1998; 55:161166.

18. Brown C, Madden PA, Palenchar DR, Cooper-Patrick L. The association between depressive symptoms and cigarette smoking in an urban primary care sample. Int I Psychiatry Med 2000; 30:15-26.

19. Bair MJ, Robinson RL, Katon W, Kroenke K. Depression and pain comorbidity: A literature review. Arch Intern Med 2003; 163:2433-2445.

20. Fishbain DA, Lewis JE, Cole B, Cutler RB, Rosomoff HL, Rosomoff RS. Variables associated with current smoking status in chronic pain patients. Pain Med 2007; 8:301-311.

21. Phillips BA, Danner FJ. Cigarette smoking and sleep disturbance. Arch Intern Med 1995; 155:734-737.

22. Wallander MA, Johansson S, Ruigómez A, García Rodríguez LA, Jones R. Morbidity Associated With Sleep Disorders in primary care: A longitudinal cohort study. Prim Care Companion I Clin Psychiatry 2007; 9:338-345.

23. Zhang L, Samet J, Caffo B, Punjabi NM. Cigarette smoking and nocturnal sleep architecture. Am J Epidemiol 2006; 164:529-537.

24. Pilowsky I, Crettenden I, Townley M. Sleep disturbance in pain clinic patients. Pain 1985; 23:27-33.

25. Morin CM, Gibson D, Wade J. Self-reported sleep and mood disturbance in chronic pain patients. Clin J Pain 1998; 14:311-314.

26. Wolfe F, Rasker JJ. The Symptom Intensity Scale, fibromyalgia, and the meaning of fibromyalgia-like symptoms. Rheumatol 2006; 33:2113-2114.

27. Goldberg MS, Scott SC, Mayo NE. A review of the association between cigarette smoking and the development of nonspecific back pain and related outcomes. Spine 2000; 25:995-1014.

28. Leboeuf-Yde C. Smoking and low back pain. A systematic literature review of 41 journal articles reporting 47 epidemiologic studies. Spine 1999; 24:14631470.

29. Fagan P, Shavers V, Lawrence D, Gibson JT, Ponder P. Cigarette smoking and quitting behaviors among unemployed adults in the United States. Nicotine Tob Res 2007; 9:241-248.
30. Lee S, Cho E, Grodstein F, Kawachi I, Hu FB, Colditz GA. Effects of marital transitions on changes in dietary and other health behaviours in US women. Int J Epidemiol 2005;34:69-78.

31. Astrand NE, Isacsson SO. Back pain, back abnormalities, and competing medical, psychological, and social factors as predictors of sick leave, early retirement, unemployment, labour turnover and mortality: a 22 year follow up of male employees in a Swedish pulp and paper company. $\mathrm{Br} /$ Ind Med 1988; 45:387-395.

32. Hagen KB, Tambs K,Bjerkedal T. A prospective cohort study of risk factors for disability retirement because of back pain in the general working population. Spine 2002; 27:1790-1796.

33. Vaerøy $H$, Helle R, Førre $O$, Kåss $E$, Terenius L. Elevated CSF levels of substance $P$ and high incidence of Raynaud phenomenon in patients with fibromyalgia: New features for diagnosis. Pain 1988; 32:21-26.

34. del Arbol JL, Muñoz JR, Ojeda L, Cascales AL, Irles JR, Miranda MT, Ruiz Requena ME, Aguirre JC. Plasma concentrations of beta-endorphin in smokers who consume different numbers of cigarettes per day. Pharmacol Biochem Behav 2000; 67:25-28.

35. Girdler SS, Maixner W, Naftel HA, Stewart PW, Moretz RL, Light KC. Cigarette smoking, stress-induced analgesia and pain perception in men and women. Pain 2005; 114:372-385.

36. Fertig JB, Pomerleau OF, Sanders B. Nicotine-produced antinociception in minimally deprived smokers and exsmokers. Addict Behav 1986; 11:239248.

37. Jamner LD, Girdler SS, Shapiro D, Jarvik ME. Pain inhibition, nicotine, and gender. Experimental and Clinical Psychopharmacology 1998; 6:96-106.

38. Lane JD, Lefebvre JC, Rose JE, Keefe FJ. Effects of cigarette smoking on perception of thermal pain. Experimental and Clinical Psychopharmacology 1995; 3:140-147.

39. Nesbitt PD. Smoking, physiological arousal, and emotional response. J Pers Soc Psychol 1973; 25:137-144.

40. Pauli P, Rau H, Zhuang P, Brody S, Birbaumer N. Effects of smoking on thermal pain threshold in deprived and minimally-deprived habitual smokers. Psychopharmacology (Berl). 
1993; 111:472-476.

41. Pomerleau OF, Turk DC, Fertig JB. The effects of cigarette smoking on pain and anxiety. Addict Behav 1984; 9:265-271.

42. Silverstein B. Cigarette smoking, nicotine addiction, and relaxation. J Pers Soc Psychol 1982; 1982:5.

43. Curtin R, Presser S,Singer E. Changes in telephone survey nonresponse over the past quarter century. Public Opinion Quarterly 2005; 69:87-98.
44. de Leeuw ED, de Heer W. Trends in Household Survey Nonresponse: A Longitudinal and International Comparison. Wiley, New York, New York, 2002.

45. Steeh C, Kirgis N, Cannon B, DeWitt B. Are they really as bad as they seem? Nonresponse rates at the end of the twentieth century. J Off Stat 2001; 17:227-247.
46. Alreck P, Settle R. The Survey Research Handbook. Irwin, Homewood, IL:1985.

47. Merkle DM, Edelman M. Nonresponse in Exit Polls: A Comprehensive Analysis. John Wiley \& Sons, Inc, New York, New York,2002

48. Groves RM. Nonresponse rates and nonresponse bias in household surveys. Public Opinion Quarterly 2006; 70:646-675. 